\title{
A Comparison of UFO and Near-Death Experiences As Vehicles For The Evolution Of Human Consciousness
}

\author{
Lorraine Davis, M.A. \\ Montague, Michigan
}

ABSTRACT: This study compares unidentified flying object experiencers (UFOErs) with near-death experiencers (NDErs) in regard to changes in attitudes toward self, others, and life in general, toward religious or spiritual orientation, and toward psychic abilities and beliefs. Kenneth Ring's questionnaires administered to NDErs (1984) were given in this study to 93 persons whose UFOE included either a light experience, an object experience, or a "close encounter." The author concludes that the UFOE, like the NDE, provides impetus toward spiritual growth, but neither as consistently nor as strongly.

The purpose of this study was to test the hypothesis that the unidentified flying object experience (UFOE), like the near-death experience (NDE), provides an impetus toward spiritual growth in terms of (a) increased positive attitudes and decreased negative attitudes toward self, others, and life in general; (b) increased belief in broader, more universal "spiritual truths" rather than narrower, denominationally oriented religious doctrines; and (c) increased psychic sensitivities.

Ms. Davis is an author and lecturer on consciousness studies. This paper was derived in part from her M.A. thesis submitted to John F. Kennedy University. Requests for reprints should be addressed to Ms. Davis at Route 1, Box 122, Eilers Road, Montague, MI 49437, from May through November, or at 616 Aleta Place, Pleasant Hill, CA 94523 from December through April. 


\section{Method}

\section{Questionnaires}

Questionnaires from Kenneth Ring's Heading Toward Omega (1984) were presented to a group of 206 UFOErs. This battery of questionnaires consisted of the (1) Background Information Sheet, which included, in addition to standard demographic data such as name, age, education, and occupation, a description of the individual's UFOE; (2) Life Changes Questionnaire, designed to test the effect of the UFOE in terms of increase, decrease, or no change in attitudes toward appreciation of life, concern for others, concern with impressing others, materialism, and quest for meaning; (3) Religious Beliefs Inventory, to test growth away from narrower denominational beliefs toward a broader spiritual universalism; (4) Psychic Experience Inventory, to explore changes in a variety of psychic abilities and beliefs, (5) Future Scenario Questionnaire, to examine what vision of the near future UFOErs now have, to see whether they report apocalyptic visions similar to those reported by some of Ring's NDErs; and (6) Behavior Rating Inventory, filled out by acquaintances who knew the experiencers well enough to report on whether or not they had changed since the experience. The latter was included in an attempt to evaluate the objective validity of the subjects' self-evaluation.

\section{Sample}

The packet of questionnaires was sent to 250 UFOErs on the mailing list of the Institute for UFO Contactee Studies (IFUFOCS), and was also distributed to 11 UFOErs who volunteered at a meeting of the Western States Division of the Mutual UFO Network (MUFON) in Mountain View, California. Of the 261 potential respondents, 55 never received the mailing because of inaccurate addresses; of the remaining 206 subjects who presumably received the packets, $93(45 \%)$ mailed back completed questionnaires.

\section{Results}

\section{Respondent Profile}

Respondents from 28 American states, Canada, Puerto Rico, and Australia ranged in age from 25 to 73 , with an average age of 44 years. Of these respondents, $60 \%$ were female, $40 \%$ male. There were 80 whites, seven Native Americans, two Hispanics, one black, one Oriental, and two of unknown ethnic background. The group consisted of 39 
married individuals, 17 single, 16 divorced, eight remarried, seven widowed, two separated, and two of unknown marital status. Religious preferences reported were 24 Protestant, 13 Catholic, 11 what might be termed "New Age" spirituality/mysticism, four nonmainline Christian, two Buddhist, two Baha'i, one Native American, three miscellaneous, 22 "no specific religion," six "no religion at all," and four unknown.

Educationally, the group median and mode reported "some college," placing the group slightly above the 1980 U.S. Census median of 12.5 years for persons 25 and older. Respondents occupied a wide range of positions in the arts, business, academia, social sciences, religion, health, management, technology, homemaking, personal services, clerical services, manufacturing, engineering, research, sales, and government; five individuals were currently unemployed, nine were retired, and five were students.

\section{UFOEs}

The 93 respondents reported almost 200 UFOEs, occurring in New Zealand, the Caribbean Islands, France, Italy, Israel, Canada, and a variety of U.S. locations. The earliest reported experience occurred in 1926 , the most recent in 1985 . Respondents ranged from $3^{1 / 2}$ to 73 years of age at the time of their experiences.

In an attempt to identify UFOE patterns that could help to define the experience, each UFOE description submitted by a respondent was examined for elements used in the description. I constructed the following composite definition by combining the 27 elements having a frequency of ten or more:

A UFO experience, which can last from just a few seconds to hours, may consist of (1) sighting an unusual light in the night sky, often moving but sometimes stationary; and/or (2) sighting an unusual object, often circular but sometimes cigar- or other-shaped, out-of-doors that often moves soundlessly through the sky, frequently in mountainous areas; and/or (3) what might be termed an "inner experience," sometimes fearful, sometimes occurring in or near a bedroom, which can involve dreams, out-of-body experiences, hypnosis, and/or time loss. Some individuals experience being on board a UFO and seeing beings who can communicate with, physically examine, advise, and/or hypnotize the UFOEr. The experience may include witnesses who are often, but not always, aware of what the UFOEr is experiencing.

Certainly the first two parts of the definition would meet with little 
objection from most UFO researchers; they add little, if anything, new to existing descriptions. However, the third part refers to an aspect of the UFOE that is less commonly found in UFOE definitions. That difference may be due to the increased incidence in my sample of "close encounterers," as defined below, in contrast to the UFOE population at large.

\section{UFOE Classification}

I elected to classify the UFOEs in terms of lights, objects, and close encounters, categories similar to those originally created by astronomer J. Allen Hynek (1972, p. 12). To permit examination of survey results from a perspective of UFOE subgroups, I classified each of the 93 respondents into one of the following UFOE categories: (a) close encounters (object or light less than 500 feet away), 64 respondents; (b) object experiencers (object greater than 500 feet away), 16 respondents; (c) light experiencers (light greater than 500 feet away), ten respondents; and (d) those with insufficient information to classify, three respondents.

Since many $(58 \%)$ of the UFOErs reported more than one kind of experience, UFOErs were classified as (a) close encounterers if any portion of their experience(s) included a classic object encounter of 500 feet or less, or contact of any sort with UFO beings, forces, etc., including contact through dreams, out-of-body experiences, psychic channeling, etc.; (b) object experiencers only if no close encounter (CE) was also involved; and (c) light experiencers only if there was no $\mathrm{CE}$ or object experienced.

The following UFOE examples illustrate the three categories, including breakdown of the CE category into three further subtypes.

CE Type 1. This might be called an externally stimulated event. That is, there is no apparent reason to believe that the light was manufactured by Respondent \#27, a 45-year-old woman who reported the following joint sighting.

We were returning to Yuma, Arizona, from the Coast, heading due east on a straight highway halfway between El Centro, California, and Yuma. This is a one-hour drive we've made many times.

I first observed what I thought to be an especially bright star directly ahead. Then I thought it must be an airplane or a helicopter because it turned blue. About this time my husband noticed it and it changed to pink and was definitely getting larger (moving toward us). 
Then it changed to yellow-white, became huge and was headed directly toward us. I closed my eyes and braced for collision. (By this time, I was sure it was a huge airliner.) The light was blinding.

When nothing happened I opened my eyes and the light was in the other lane of the highway. Both of us now thought it was an airliner making an emergency landing, but as it passed us it made no sound. We looked at one another and said in unison: "What the - - was that?"

I turned to watch it continue down the highway, fearing it would overrun somebody. As it receded, it rose into the air straight up, heading just a little north of west until it disappeared from view.

We looked for other cars hoping someone else had seen it, but the highway was deserted.

We had left El Centro expecting to arrive home in time to catch a 10:00 TV program. That is, we left there at 7:30 California time, which should have brought us home at 9:30 Arizona time. When we arrived home, the half-hour show was over and it was 10:30.

We were dumbfounded by the time loss and didn't connect it with the light until much later, when I read of such happenings among the tons of books I brought home from the library on UFOs. We saw no shape, only an enormous light.

CE Type 2. This type is most readily characterized as "inner." The example includes recall under hypnosis and even uncertainty as to "how much is 'real' and how much is 'imagination.' " Respondent \#15, a 38-year-old male, described his UFOE as follows.

First, let me point out that I have very little conscious recall of the events-only enough to cause me to request hypnotic regression to stimulate further recall. Hence I am not at all sure how much is "real" and how much is "imagination."

Having said that, the "incident" happened while on a camping trip with a friend in the fall of 1980 in the southern Colorado mountains, near the town of Crestone. Sometime in the night, or early morning hours, a large saucer-shaped craft came up the canyon where we were-hovered just over the treetops-shined some type of greenish light on us which caused us to become paralyzed, and then, "transported" us (me at least) aboard.

I experienced several puzzling circumstances which eventually led me to a face-to-face meeting with a "little" alien (??) whom I felt I knew and who gave me some guidance and counsel, and then "transported" me back to my sleeping bag when I "determined" I would remember before I went back to sleep. (He told me I would remember nothing of the "encounter," only the messages, and they only in a subconscious way.) There is much more, of course, but that is the essence of the event.

CE Type 3. This category includes the atypical cases that do not specifically refer to UFO details. They do not mention UFOs or beings, 
yet involve experiences of light or contact similar to those in a UFOE. These respondents were on the IFUFOCS list presumably because such cases sometimes elicit a UFO connection under hypnosis. Accordingly I elected not to exclude them from my study. Respondent $\# 22$, a 56-year-old homemaker whose experience occurred 30 years ago while she was a graduate student, presented a very detailed description complete with drawings. For the sake of brevity I shall paraphrase her description, with the exception of a brief final quote.

At approximately 2 a.m. a small white light entered through the top of her bedroom window, grew in size and color (yellow-orange-red) as it traveled down the window to the floor, along the baseboard and toward the bed. It changed from a ball to the shape of a fire to a golden glow with nondescript lines and shadows. It left the room following exactly the same pattern but in reverse order. The experience left the respondent "frozen" on the spot and trembling. She subsequently checked the entire house for signs of fire but found none. She concluded her description by saying: "it was not unusual for me to awaken and study from 2 a.m. to 5 a.m. . . My mind was sharp and functioning best at this time of morning. This was not a dream?"

Object. Respondent \#5, a 72-year-old retired widow whose 1975 UFOE is typical of an object experience, described it as follows.

I was watching the Smothers Brothers on TV. During the commercial break I opened my living room door to let my dog in and heard a sound above my home. I thought a helicopter was landing. My dog had hurried to her bed. I had to cross the porch and step down to look up over my roof. I expected to see a high quality special helicopter as it had a smooth sound. A man in Pittsburgh said he heard a sound like a twirling rope. I feel his description of the sound was more accurate. I looked higher up. I saw a large football-shaped vehicle moving slowly from east to west or northeast to southwest (I figured) toward Pittsburgh. I was in awe as it was about 1,000 feet high-very large. I thought at first it was a balloon but it was covered with projections much like antennas. A glowing ball was going from the object to the antenna's end-and returned. I feel this was an outside source of energy. Venus was bright, so it helped me identify these antennaprojections and the light was traveling to and from all over the caterpillar-like projections. The entire object was aglow, encircled by a red-green golden ring. My neighbor came out and looked when I ran over and rapped on her door. She said, "My God, is it the end of the world?" This happened at 8:30. At 10:30 I was still in awe and had phoned friends to look - then realized it had left. I seem to remember slipping on my neighbor's steps and had a red mark below my knee. Next morning when I combed my hair it didn't want to lay down. Seemed full of electricity. Since then my skin is allergic to most 
everything and I get small growths on my arms like clustered mushrooms. Also top of head and front of neck and top of back.

Light. Respondent \#80 is a 28-year-old graduate engineering student working on his thesis. He reported the following joint 1981 light experience, which was corroborated by Respondent \#64.

I observed while on a backpacking trip in the Bridger Wilderness area of the Wild River Mountains, an orange light approximately four to eight times the diameter of the largest star. This orange light moved across the sky at about the speed of a low-flying airplane. However, no sound came from the orange light. This first orange light went from one side of the sky to the other in approximately a straight line. Shortly after it disappeared a second orange light came from the same direction as the first one. The second one appeared identical to the first one and moved about the same speed. The second orange light moved approximately halfway across the sky and then it executed what appeared to be an instantaneous 90-degree turn. Thereafter it continued moving in a straight line until it disappeared over the top of the trees. (Note: The orange lights appeared to be considerably higher than a low-flying plane that would be going at that speed would have to be, i.e., the lower a plane flies the faster it "appears" to be flying. The orange lights seemed lower than a high flying jet.) Also, two friends saw a light traverse the sky before I turned over to look. I was trying to go to sleep and when they started talking I thought they were just seeing an airplane.

\section{Life Changes Questionnaire (LCQ)}

In Ring's research with near-death experiencers (1984), 23 LCQ statements were used to define five value clusters: (a) appreciation of life (2 statements); (b) concern for others (8 statements); (c) quest for meaning (6 statements); (d) concern with impressing others (3 statements); and (e) materialism (4 statements). Table 1 lists the responses of NDErs from Ring's (1984) study and of UFOErs from the present study to these five value clusters in terms of increase in positive values and decrease in negative values.

UFOErs and NDErs both show far more increases than decreases in appreciation of life. However, that effect is significantly smaller among UFOErs than among NDErs. Both groups also show far more increases than decreases in concern for others; again the effect is significantly smaller among UFOErs than among NDErs. Both groups furthermore reported far more increases than decreases in quest for meaning; for this effect, the difference between UFOErs and NDErs was not significant. 


\begin{tabular}{|c|c|c|c|}
\hline Values cluster & Response & $N D E r s^{a}$ & UFOErs \\
\hline \multirow[t]{2}{*}{ Appreciation of life $\mathrm{b}^{\mathrm{b}}$} & increased & 23 & 60 \\
\hline & unchanged or decreased & 3 & 31 \\
\hline \multirow[t]{2}{*}{ Concern for others ${ }^{b}$} & increased & 23 & 61 \\
\hline & unchanged or decreased & 3 & 31 \\
\hline \multirow[t]{2}{*}{ Quest for meaningc } & increased & 24 & 71 \\
\hline & unchanged or decreased & 2 & 21 \\
\hline \multirow{2}{*}{$\begin{array}{l}\text { Interest in } \\
\text { impressing others }\end{array}$} & increased or unchanged & 12 & 61 \\
\hline & decreased & 13 & 31 \\
\hline \multirow{2}{*}{$\begin{array}{l}\text { Interest in } \\
\text { materialism }\end{array}$} & increased or unchanged & 14 & 61 \\
\hline & decreased & 13 & 30 \\
\hline
\end{tabular}

About a third of the UFOErs and a half of the NDErs reported decreased interest in impressing others and in materialism. For these changes, the UFOErs and NDErs did not differ significantly from each other.

UFOErs thus responded similarly to Ring's NDErs in their increased appreciation of life, concern for others, and quest for meaning, and in their decreased interest in impressing others and in materialism. However, UFOErs' value changes suggesting spiritual growth were neither as consistent nor as strong as those shown by NDErs. Not only did fewer UFOErs respond to statements in the appropriate direction to indicate spiritual growth, but those who did so tended to choose the milder "increased" or "decreased" responses rather than "strongly increased" or "strongly decreased." For two of the selected values clusters, the difference between the NDErs and UFOErs was statistically significant.

There was no clearcut pattern of differences among the UFOE subgroups described above.

\section{Religious Beliefs Inventory (RBI)}

Spiritual growth was measured with Ring's RBI, a list of 12 statements of religious belief, six of which reflect conventional Christian 
beliefs (e.g., "Eternal life is a gift of God only to those who believe in Jesus Christ as savior and Lord") and six of which reflect spiritual universalism (e.g., "The essential core of all religions is the same"). Respondents were asked to indicate whether they were more or less inclined to agree with each statement than they had been prior to their UFOEs.

Ring (1984) calculated a "spiritual universalism scores" based on the double difference method, i.e., the sum of spiritual universalism statements the respondent is more inclined to agree with minus those he or she is less inclined to agree with, plus the sum of conventional Christian statements the respondent is less inclined to agree with minus those he or she is more inclined to agree with. Ring's 172 respondents included 76 NDErs; 30 "non-NDErs," individuals who had come close to death but did not report NDEs; and 66 control subjects who had never come close to death. Mean scores for all three groups were positive, indicating a net change in the direction of spiritual universalism (since their near-death event for the first two groups, and over the previous decade for the control group). The spiritual universalism scores averaged 5.84 for NDErs, 4.30 for non-NDErs, and 3.85 for the control group.

Mean scores of all UFOEr groups fell between those of the NDErs and non-NDErs. Object experiencers had the highest UFOEr score, 5.80 , close to that of Ring's NDErs; close encounterers averaged 4.91; light experiencers, with the lowest score among UFOErs, 4.40, still scored higher than did Ring's non-NDEr group. The average score of all 91 UFOErs who completed the RBI was 5.00. I could not test the statistical significance of differences in spiritual universalism scores between UFOErs and Ring's subjects, because Ring reported only mean scores and not standard deviations. However, it is clear from these means that UFOErs' scores more closely resemble those of people who have had a near-death episode than those of control subjects who have never come close to death.

Ring (1984) also reported the proportion of respondents who had extremely high spiritual universalism scores, i.e., at least eight out of a possible twelve. Again, the UFOErs fell between NDErs and nonNDErs in spiritual universalism: among NDErs, $49 \%$ had extremely high scores; among UFOErs, 36\%; non-NDErs, 30\%; and control respondents who had never been close to death, fifteen percent. Chisquared tests comparing UFOErs with NDErs and with non-NDErs yielded no significant differences.

\section{Psychic Experience Inventory (PEI)}

The PEI addresses changes in frequency of 14 varieties of paranormal phenomena. Ring (1984) calculated a composite psychic experience 
index by summing the number of items for which an increase in incidence was reported following an NDE. Ring found that $58 \%$ of NDErs scored eight or higher on the composite psychic experience index; in the present study, $53 \%$ of UFOErs scored eight or higher.

Item analyses showed remarkable similarities between NDErs and UFOErs. The two psychic phenomena reported to have the highest frequency of increase among NDErs, experiences of inner wisdom (96\% of NDErs) and intuition (80\%), also had the highest frequency of increase among UFOErs (69\% and $72 \%$ respectively). Those items that were reported as increased by half or more of Ring's NDErs (telepathy, synchronicity, clairvoyance, knowing what someone will say before he or she says it, unexpected rescues from plights, precognition, and spirit guides) were also reported as increased by $42 \%$ to $63 \%$ of UFOErs in this study. Two deja vu items reported as increased by slightly more than a third of the NDErs were also reported as increased by $32 \%$ and $37 \%$ of UFOErs. As on the Life Changes Questionnaire, UFOErs reported changes similar to those of NDErs, but of smaller magnitude.

UFOE subgroups differed in their reported increases in psychic experiences. A greater proportion of close encounterers reported increases, ranging from a low of $38 \%$ reporting increased deja $v u$ to a high of $80 \%$ reporting increased intuition. Fewer object UFOErs and light UFOErs reported increases: among object experiencers, as few as seven percent reported increased retrocognition, while as many as $67 \%$ reported increased inner wisdom; among light experiencers, none reported increased out-of-body experiences, while as many as $67 \%$ reported increased intuition.

The PEI also addresses changes in belief in various paranormal phenomena. Ring (1984) had NDErs rate belief in God, life after death, extrasensory perception, psychic or spiritual healing, spirit guides, reincarnation, out-of-body experiences, demonic possession, and astrology along a continuum from +2 , reflecting greatly increased belief, to -2 , reflecting greatly decreased belief. In the present study UFOErs likewise rated belief in those nine items, plus UFOs, extraterrestrial life, the collective unconscious, Atlantis or other lost continents, the Bermuda Triangle, and unusual animal life such as the Loch Ness monster or Bigfoot.

More than half the NDErs reported increased belief in seven of the nine items; more than half the UFOErs reported increased belief in five of those same nine items. Percent of respondents reporting increased belief in those items ranged from $60 \%$ to $96 \%$ for NDErs, and from $51 \%$ to $58 \%$ for UFOErs. In both groups, a majority of respondents reported no change in belief in demonic possession or in astrology. Thus, for paranormal beliefs as well as reported paranormal experi- 
ences, changes following UFOEs paralleled those following NDEs, but were of smaller magnitude.

Ring found NDErs' increased belief to be "especially marked for those concepts that these respondents are likely to feel they experienced during their NDE itself" (1984, p. 173); e.g., mean change scores were 2.00 for belief in God, 1.92 for belief in life after death and in extrasensory perception, and 1.80 for belief in out-of-body experiences. UFOErs likewise showed greatest increases in belief in those items they experienced during their UFOEs; the highest scores among UFOErs were 1.26 for belief in UFOs, 1.06 for belief in out-of-body experiences, and 1.05 for belief in extraterrestrial life.

\title{
Future Scenario Questionnaire (FSQ)
}

Ring reported that many NDErs experienced a planetary vision, or global precognition, and he found that many respondents, particularly those who reported more profound NDEs and had encountered a being of some sort, described a common vision of the world's near future that he summarized as follows:

\begin{abstract}
There is, first of all, a sense of having total knowledge, but specifically one is aware of seeing the entirety of the earth's evolution and history, from the beginning to the end of time. The future scenario, however, is usually of short duration, seldom extending much beyond the begin. ning of the twenty-first century. The individuals report that in this decade there will be an increasing incidence of earthquakes, volcanic activity, and generally massive geophysical changes. There will be resultant disturbances in weather patterns and food supplies. The world economic system will collapse, and the possibility of nuclear war or accident is very great (respondents are not agreed on whether a nuclear catastrophe will occur). All of these events are transitional rather than ultimate, however, and they will be followed by a new era in human history marked by human brotherhood, universal love, and world peace. Though many will die, the earth will live. While agreeing that the dates for these events are not fixed, most individuals feel that they are likely to take place during the $1980 \mathrm{~s}(1984$, p. 197).
\end{abstract}

Based on these visions, Ring constructed the FSQ, in which respondents choose the most likely of ten different future scenarios ranging from improvement in world conditions to massive deterioration; three of those ten choices are consistent with parts of the prototypical vision quoted above. Ring reported that $33.3 \%$ of his sample of NDErs endorsed those three catastrophic scenarios, as contrasted to $26.8 \%$ of his non-NDEr group. In the present study, $26.9 \%$ of UFOErs endorsed those three scenarios. 
As with increases in psychic experiences, close encounterers proved to be different from object and light UFOErs in their global precognitions. The three catastrophic scenarios were selected by $31 \%$ of the close encounterers, but by only $13 \%$ of the object UFOErs and $20 \%$ of the light UFOErs.

\section{Behavior Rating Inventory (BRI)}

The BRI is an 11-item instrument designed to allow friends or relatives, knowledgeable about the respondent's values and beliefs before and after the experience, to describe what changes, if any, they perceive in the individual who had the experience. Ring (1984) reported a mode of eight out of those 11 items were answered in the same way by both the experiencer and the friend or relative who completed the BRI, and interpreted that result as evidence that "the changes that NDErs attribute to themselves are also perceived and corroborated by individuals who knew them well (and, presumable, usually best) both before and after their experience" (1984, pp. 140-141).

In the present study, 48 BRIs were completed describing 46 UFOErs, half the total sample; $61 \%$ of the BRI responses were identical to the responses the UFOErs gave describing themselves. As in Ring's sample, the modal number of responses answered in the same way by respondent and friend or relative was eight out of 11 .

\section{Discussion}

I suggested above that the NDE and UFOE may be somewhat different but comparable experiences in higher consciousness. To explore the similarities between these two types of experience, I shall review Ring's examination of the various stages and elements of the NDE from a parapsychological or holographic perspective (1980), and briefly examine analogous elements of the UFOE. Emergent similarities will elucidate how the UFOE, like the NDE, may be an experience in higher consciousness.

\section{Peace and Out-of-Body Experience}

In discussing stages 1 and 2, peace and out-of-body components, Ring concluded that something seems to separate from the physical body 
and take on an existence of its own, one in which there is continued awareness of both self and environment. The NDE is first of all, then, in Ring's view, an out-of-body experience.

OBEs were common in this sample of UFOErs, being reported by 57 individuals (61\%). Some of those OBEs occurred during the UFOE. Almost a quarter of the high scorers on the PEI reported that OBEs had become more frequent since the UFOE. My respondents as a group reported an increase in belief in OBEs second only to increase in belief in UFOs; the OBE was the only concept for which both NDErs and UFOErs reported a major increase in belief. As it seems clear that many of my UFOErs thus experienced being able to function in another realm or level of consciousness, I would suggest that their UFOEs were also exercises in another realm.

The sense of peace commonly experienced by NDErs in stage one is by and large absent from the UFOE. My respondents reported a mixture of positive and negative feelings, including, in decreasing frequency of report, fear, feeling of requesting or welcoming the UFO, reassurance, joy, anger, feeling of protection, sadness, excitement, calm, strangeness, wanting to leave with the UFO, and secrecy. Emotional reactions to UFOEs were thus quite varied, in contrast to the positive reaction experienced by most NDErs.

\section{Tunnel and Light}

In analyzing stages 3 and 4, the tunnel and the light, Ring suggested that:

these extraordinary phenomena represent ... a shift in levels of consciousness. ... When consciousness begins to function independent of the physical body, it becomes capable of awareness of another dimension-let us, for ease of reference, simply call it for now a fourth dimension. Most of us, most of the time,. function in the three-dimensional world of ordinary sensory reality. According to the interpretation I am offering, this reality is grounded in a body-shaped consciousness. When one quits the body - either at death or voluntarily, as some individuals have learned to do-one's consciousness is then free to explore the fourth-dimensional world. This means, as we will see, that the elements of the core experience with which we are here concerned are not unique to near-death states but are potentially available to anyone who learns to operate his consciousness independent of the physical body. Any trigger that brings about this release may induce such experiences. It happens that coming close to death, for reasons that are obvious, is a reliable trigger effecting this release of consciousness. But to repeat: Anything that sets consciousness free from 
the body's sensory-based three-dimensional reality is capable of bringing about an awareness of the fourth dimension. There are numerous accounts of these experiences by individuals who have entered into this realm-without dying. (1980, pp. 234-235)

I would suggest that UFOErs are among those who have entered this realm, that their experience somehow involves being released from "the body's sensory-based three-dimensional reality . . . bringing about an awareness of the fourth dimension."

Just as the OBE occurs in NDEs and in UFOEs, the element of light is common to both experiences. Light is one of the most frequently reported elements in the UFOE. The 93 respondents in this study mentioned light a total of 150 times.

In contrast, a tunnel was mentioned by my respondents only eight times. Ring quoted consciousness researcher Itzhak Bentov as saying in a personal communication that the tunnel effect:

is a psychological phenomenon whereby the consciousness experiences "motion" from one "level" to the other. It is the process of adjustment of the consciousness from one plane of reality to another. It is usually felt as movement. This is so only for people . . . for whom this is new. For people who are used to going into the astral or higher levels, this tunnel phenomenon does not happen anymore. (Ring, 1980, p. 238)

Perhaps most of my sample of UFOErs no longer need to experience the tunnel effect, as $68 \%$ of those reporting OBEs indicated having had multiple OBEs. Alternatively, the necessary sense of "motion from one level to the other" might be provided by the movement so often associated with objects or lights in the UFOE. Moving lights were reported 42 times and moving objects 20 times, and the object or light was seen while in a moving car 27 times.

\section{World of Light}

The final NDE stage in Ring's prototypical model, the "world of light," is entered after passing through the tunnel.

At this point, the individual perceives a realm of surpassing beauty and splendor and is sometimes aware of the "spirits" of deceased relatives or loved ones.

What is this world? . . . It is another frequency domain-a realm of "higher" frequencies . . . a realm that is created by interacting thought 
structures. These structures or "thought-forms" combine to form patterns, just as interference waves form patterns on a holographic plate. And just as the holographic image appears to be fully real when illuminated by a laser beam, so the images produced by interacting thought-forms appear to be real. (Ring, 1980, pp. 246-247)

Ring extended this interpretation to spirit forms:

Just as object-forms are, theoretically, from a holographic point of view, a function of interacting mind patterns, so, too, are encounters with "persons" in "spirit bodies." Such "entities" are, then, the product of interacting minds attuned to a holographic domain in which thought alone fashions reality. The fact that communication between the near-death survivor and the "spirit-form" is usually said to be telepathic in nature again points to a world of existence where thought is king. (1980, p. 248)

I would suggest that the entities met by UFOErs fall into the same category as NDE "spirit bodies"; they communicate by telepathy and otherwise live in a world where thought seems to be king.

Ring then addressed the rare instances when near-death survivors have hellish experiences:

In my view, what is happening in these cases is that the individual is "passing through" a lower frequency domain (although he may occasionally-temporarily - "get stuck" there). This domain is also a holographic reality and is organized in precisely the same way as the paradisical realm we have already considered. The principle difference is in the nature of the minds that are interacting to create this reality. (1980, p. 249)

UFOErs don't usually report entering a "world of light." Their experience takes them to a different kind of world, not the hellish one alluded to above, but still not the glorious realm of light either. Instead of being surrounded by a sense of utter, ineffable peace and love, many UFOErs, finding themselves apparently on board a UFO or otherwise in contact with apparent UFO beings, describe a more impersonal, less caring experience, one in which the emphasis is not on being totally loved but on being examined and then perhaps being given information that one may or may not be allowed to remember.

\section{Kundalini Hypothesis}

Another possible interpretation of the similarities and differences between the NDE and UFOE is to consider them as variations in 
development in kundalini energy. Eastern mysticism has long believed in the existence of a bioenergy that is said to lie latent at the base of the spine like a coiled snake. This kundalini energy is believed to bring spiritual enlightenment when it is set free by rising up through the body's seven energy centers or chakras. Chakras open usually through meditation or other spiritual practices, but spontaneous openings may occur.

It was suggested to me by parapsychologist Sharon Solfvin (personal communication) that NDErs may experience an opening of the fourth or heart chakra, as evidenced by the sense of profound love with which they return from their experience. It is possible that the UFOEr may experience an opening in one of the other chakras, perhaps the third or solar plexus chakra, which seems to relate more to the question of ego and identity.

Japanese scientist and kundalini researcher Hiroshi Motoyama (1981) has stated not only that psychic abilities are awakened by kundalini release, but that the types of psychic abilities vary according to which chakras are opened. He stated that the first three chakra openings result in predominantly extrasensory abilities, such as telepathy, clairvoyance, and psychometry, whereas fourth chakra openings lead to psychic powers that can create new energy and transmit it to others, such as psychokinesis and psychic healing. Further studies of possible variations in psychic abilities among NDErs and UFOErs might shed additional light on the differences between the two groups.

\section{Nature of the UFOE}

At first glance, the various types of UFOEs seem to have little in common; the close encounter type of experience seems quite different from one involving the sighting of a light or object from afar. However, there were no clear-cut differences in aftereffects among the three subgroups, with the exception that the close encounterers consistently scored higher than the object UFOErs and light UFOErs on the Psychic Experience Inventory and tended more frequently to endorse a catastrophic future vision on the Future Scenario Questionnaire.

It appears then that the commonalities among UFOErs are greater than their differences. Perhaps what they share in common is the sense that the UFOEr has experienced an important contact with something larger than the limited self with which one usually identifies. Although that connection is understandably clearer for the close encounterer, it is nevertheless present in all types of UFOE. One 
senses both a longing for that unknown something out there and a confusion about having connected with it. UFOErs seem to be asking what existence is about, and often they receive information in their experiences.

I suspect that the UFOEr is on a search, looking for the meaning and order that modern-day people lack in their lives. I do not say it is a conscious search. In fact, it is probably because people today are still largely unaware of the higher self within that they look outward for their answers, and in the process find lights and objects and beings within them who help make the vital connection they aren't even aware they're looking for.

I believe that the UFOEr is searching for a way in which to make that most important change in direction referred to as "the turn" in Arthur Young's process theory of the evolution of consciousness (Young, 1976, 1988). The UFOErs' choice, subconscious though it may be, is to make that crucial change in direction, to choose growth and not entropy. And he or she does so by taking the path that apparently comes most naturally in this age of space technology, creating experience in terms of UFOs, extraterrestrial beings, and the like. By "creating" I do not mean to imply exercising mere idle imagination having no foundation in truth, but rather connecting creatively with higher levels of consciousness capable of producing experiences beyond those ordinarily known in the physical realm.

My suggestion is that the UFOE is simply another way in which humanity is trying to make contact with the higher consciousness that lies latent within each individual. As Ring wrote, "The principle difference is in the nature of the minds that are interacting to create this reality" (1980, p. 249). Those who subconsciously "elect" to have a UFOE seem to be at a point of inquiry rather than solution. They are still searching, but their end goal is the same as that of the NDEr: spiritual growth.

I contend that through their UFO experience, UFOErs have subconsciously opted to make the turn in Young's model of consciousness toward greater spiritual growth. This choice begins them on the long, arduous task of leaving behind the old and taking on the new. We see those first steps in the changed life values, spirituality, and psychic sensitivities highlighted in this study.

\section{Conclusion}

My hypothesis was that the UFOE, like the NDE, provides an impetus toward spiritual growth in terms of : (a) increased positive attitudes 
and decreased negative attitudes toward self, others, and life in general; (b) increased belief in broader, more universal spiritual truths rather than narrower, denominationally oriented religious doctrine; and (c) increased psychic sensitivities.

UFOErs in this study did, indeed exhibit these changes, but not as consistently or as strongly as NDErs. Proportionally fewer UFOErs responded in the appropriate direction and their responses tended to be of smaller magnitude; the quantitative differences between NDErs and UFOErs were statistically significant.

My findings support the concept of the UFOE as similar but not equal to the NDE. I contend that the NDE, with its emphasis on love as life's motivating force, provides a more powerful impetus to spiritual growth than the UFOE, which seems to consist more of inquiry and information-seeking than of being given the answer.

The value of this study lies largely in its pilot nature, introducing evidence of a new way to view the UFOE. The limitations of this study suggest the following modifications that should be corrected in future research:

1. a more random sample of UFOErs should be sought, as my sample consisted mainly of the UFOE population of one investigative group;

2. questionnaires should be administered to a scientifically selected control group of non-UFOErs and non-NDErs;

3 . instruments measuring spiritual growth might also be given to comparable groups who have had experiences similar to the NDE or UFOE, such as kundalini openings, drug-induced altered states of consciousness, or spiritual visions;

4. less esoteric traumatic experiences such as divorce, bankruptcy, and bereavement might also be studied to see whether they carry similar impetus for spiritual growth; and

5. comparative study should be made of the differences in psychic abilities between NDErs, UFOErs, and other groups experiencing higher consciousness.

\section{References}

Hynek, J. A. (1972). The UFO Experience, Chicago, IL: Regnery.

Motoyama, H. (1981). Theories of the Chakras: Bridge to Higher Consciousness. Wheaton, IL: Theosophical Publishing House.

Ring, K. (1980). Life at Death. New York, NY: Coward, McCann \& Geoghegan.

Ring, K. (1984). Heading Toward Omega. New York, NY: Morrow.

Young, A. (1976). The Reflexive Universe. San Francisco, CA: Robert Briggs Associates.

Young, A. (1988). Science, spirit, and the soul. Journal of Near-Death Studies, 6. 